\title{
Renewable Energy Data Explorer User Guide
}

July Tran, Nick Grue, and Sadie Cox National Renewable Energy Laboratory

NREL is a national laboratory of the U.S. Department of Energy Office of Energy Efficiency \& Renewable Energy Operated by the Alliance for Sustainable Energy, LLC

This report is available at no cost from the National Renewable Energy Laboratory (NREL) at www.nrel.gov/publications.

Technical Report

NREL/TP-6A20-71532

May 2018

Contract No. DE-AC36-08GO28308 


\section{Renewable Energy Data Explorer User Guide}

July Tran, Nick Grue, and Sadie Cox National Renewable Energy Laboratory

Prepared under Task Nos. AEG-P-00-09-00003-00, IAG-172050
National Renewable Energy Laboratory 15013 Denver West Parkway Golden, CO 80401

303-275-3000 • www.nrel.gov
NREL is a national laboratory of the U.S. Department of Energy Office of Energy Efficiency \& Renewable Energy Operated by the Alliance for Sustainable Energy, LLC

This report is available at no cost from the National Renewable Energy Laboratory (NREL) at www.nrel.gov/publications.

\section{Technical Report}

NREL/TP-6A20-71532

May 2018

Contract No. DE-AC36-08G028308 


\section{NOTICE}

This report was prepared as an account of work sponsored by an agency of the United States government. Neither the United States government nor any agency thereof, nor any of their employees, makes any warranty, express or implied, or assumes any legal liability or responsibility for the accuracy, completeness, or usefulness of any information, apparatus, product, or process disclosed, or represents that its use would not infringe privately owned rights. Reference herein to any specific commercial product, process, or service by trade name, trademark, manufacturer, or otherwise does not necessarily constitute or imply its endorsement, recommendation, or favoring by the United States government or any agency thereof. The views and opinions of authors expressed herein do not necessarily state or reflect those of the United States government or any agency thereof, including the United States Agency for International Development.

This report is available at no cost from the National Renewable Energy Laboratory (NREL) at www.nrel.gov/publications.

Available electronically at SciTech Connect http:/www.osti.gov/scitech

Available for a processing fee to U.S. Department of Energy and its contractors, in paper, from:

U.S. Department of Energy

Office of Scientific and Technical Information

P.O. Box 62

Oak Ridge, TN 37831-0062

OSTI http://www.osti.gov

Phone: 865.576.8401

Fax: 865.576.5728

Email: reports@osti.gov

Available for sale to the public, in paper, from:

U.S. Department of Commerce National Technical Information Service 5301 Shawnee Road Alexandria, VA 22312

NTIS http://www.ntis.gov

Phone: 800.553 .6847 or 703.605 .6000

Fax: 703.605.6900

Email: orders@ntis.gov 


\section{Acknowledgements}

The authors would like to thank Jennifer E. Leisch from the United States Agency for International Development, and Andrea Watson, Jessica Katz, Nathan Lee, Evan Rosenlieb, Ricardo Oliveira, Dave Mooney, Nate Blair, and Pitoon Junthip of Abt Associates and the USAID Clean Power Asia program.

This work was authored in part by Alliance for Sustainable Energy, LLC, the manager and operator of the National Renewable Energy Laboratory for the U.S. Department of Energy (DOE) under Contract No. DEAC36-08GO28308. Funding provided by the United States Agency for International Development. The views expressed in the report do not necessarily represent the views of the DOE or the U.S. Government. The U.S. Government retains and the publisher, by accepting the article for publication, acknowledges that the U.S. Government retains a nonexclusive, paid-up, irrevocable, worldwide license to publish or reproduce the published form of this work, or allow others to do so, for U.S. Government purposes. 


\section{Table of Contents}

About the Renewable Energy Data Explorer (RE Data Explorer)....................................................... 1

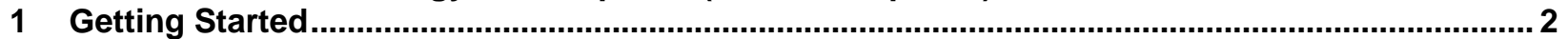

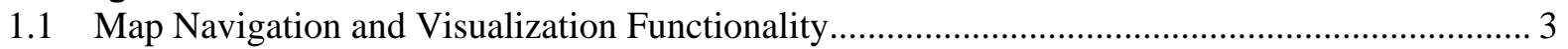

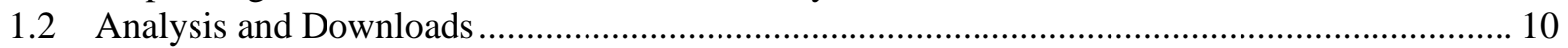

2 Technical Potential Tool: Using Limits and Exclusions to Create Scenarios.............................. 18

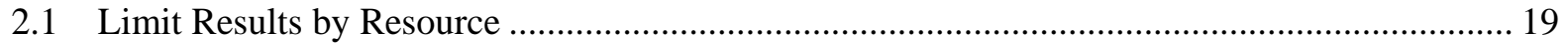

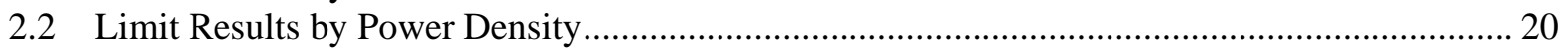

2.3 Limit Results by Proximity (to Roads and Transmission) ..................................................... 21

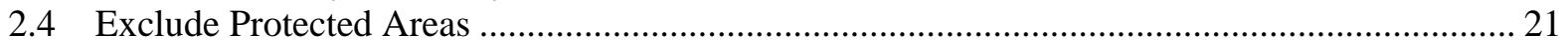

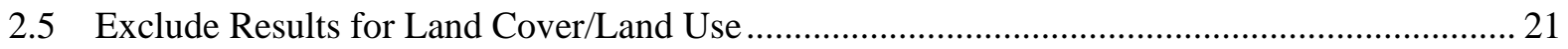

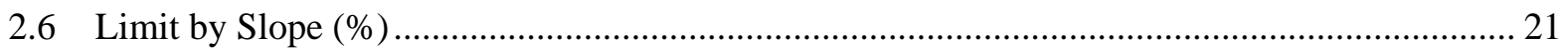

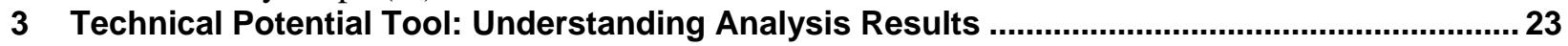

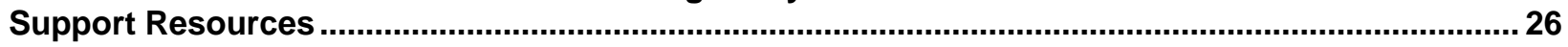

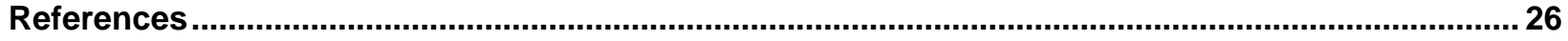

Appendix: Resource Analysis to Produce Capacity Factors ................................................... 28

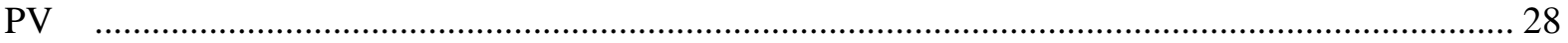

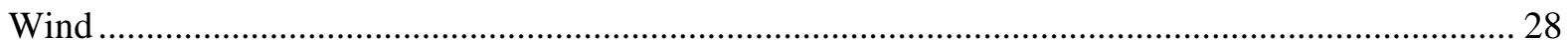

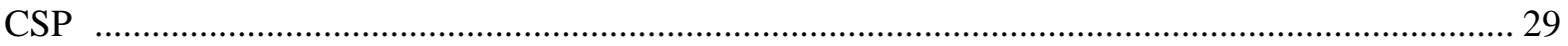

\section{List of Figures}

Figure 1. Resource, technical, economic, and market potential of renewable energy.....................14

Figure 2. Three examples of technical potential scenarios for fixed-tilt solar PV in Vietnam .......... 19

\section{List of Tables}

Table 1. Parameters and Guidance for Using Limits and Exclusions

\section{List of Text Boxes}

Text Box 1. The Temporal Aspects of a Data Set 


\section{About the Renewable Energy Data Explorer (RE Data Explorer)}

The Renewable Energy Data Explorer (RE Data Explorer) is a dynamic, web-based geospatial analysis tool that facilitates renewable energy decision-making, investment, and deployment. It brings together renewable energy resource data and other modeled or measured geographic information system (GIS) layers, including land use, weather, environmental, population density, administrative, and grid data. By combining these data sets, decision makers can explore and synthesize information about renewable energy potential to guide planning, policymaking, and investment. Data in the RE Data Explorer comes from a variety of sources, including partner government ministries and research institutions, the National Renewable Energy Laboratory's (NREL) country resource assessment programs, the World Bank ${ }^{1}$ and other third-party data providers.

The RE Data Explorer is housed within the broader RE Data Explorer website (www.reexplorer.org), which provides resources, trainings, data sources, and expert assistance to support renewable energy geospatial analysis and decision making. Within the RE Data Explorer, the Data Catalog provides a central location for discovery of the renewable energy resource and GIS data that powers the RE Data Explorer, as well as a place for researchers to contribute or document data in support of the RE Data Explorer.

NREL partners with the United States Agency for International Development (USAID) and several other institutions to develop the RE Data Explorer for various countries. To learn more, please visit www.re-explorer.org.

\footnotetext{
${ }^{1}$ As a notable example, global solar data for several RE Data Explorer countries were provided by The World Bank with funding from the Energy Sector Management Assistance Program (ESMAP) under a global initiative on Renewable Energy Resource Mapping (esmap.org/re mapping).
} 


\section{Getting Started}

Users can access the RE Data Explorer at www.re-explorer.org/launch.html. At the time of publication, the RE Data Explorer is available for Afghanistan, Bangladesh, Ghana, India, Indonesia, Central Asia, Kenya, Lower Mekong Region of Asia (Cambodia, Lao PDR, Myanmar, Thailand, and Vietnam), Mexico, Nepal, Pakistan, Peru, and the Philippines. To see countries that have been added to the RE Data Explorer since the publication of this user guide, please visit www.re-explorer.org/launch.html.

From the RE Data Explorer homepage (www.RE-Explorer.org), users can click on Launch Explorer from the top navigation bar to access the RE Data Explorer. A user can then click on a country and begin using the RE Data Explorer. Users can also access the RE Data Explorer for an individual country using a URL like https://maps.nrel.gov/rede-country. For example, for India, the URL is maps.nrel.gov/rede-india.

After launching the RE Data Explorer, users will have two options:

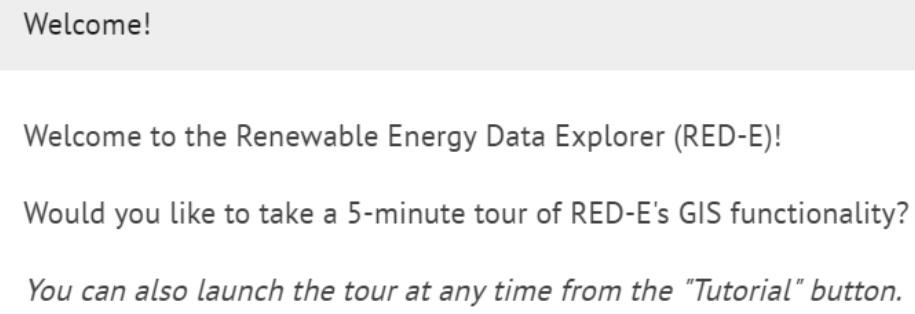

- Take Tutorial: Select this option for a short wizard-based tutorial that walks through the features of the RE Data Explorer. This option is recommended for all first-time users and users that are less familiar with the RE Data Explorer.

- Use Tool: Select this option to begin using the RE Data Explorer without taking the tutorial.

To access the tutorial at any time, click Tutorial in the navigation bar (described in Section 1.1). 


\subsection{Map Navigation and Visualization Functionality}

The RE Data Explorer is a map-based geospatial application. From any map, users can interact with the RE Data Explorer in three ways, each of which is indicated in red and described in detail below.

- Maps Controls (upper right): Change the base map and select an area.

- Visualization and Analysis Tabs (upper left): Interact with data layers and run queries or use analysis tools.

- Navigation Bar (top right): Reset the map, print it, submit feedback, or launch tutorials.

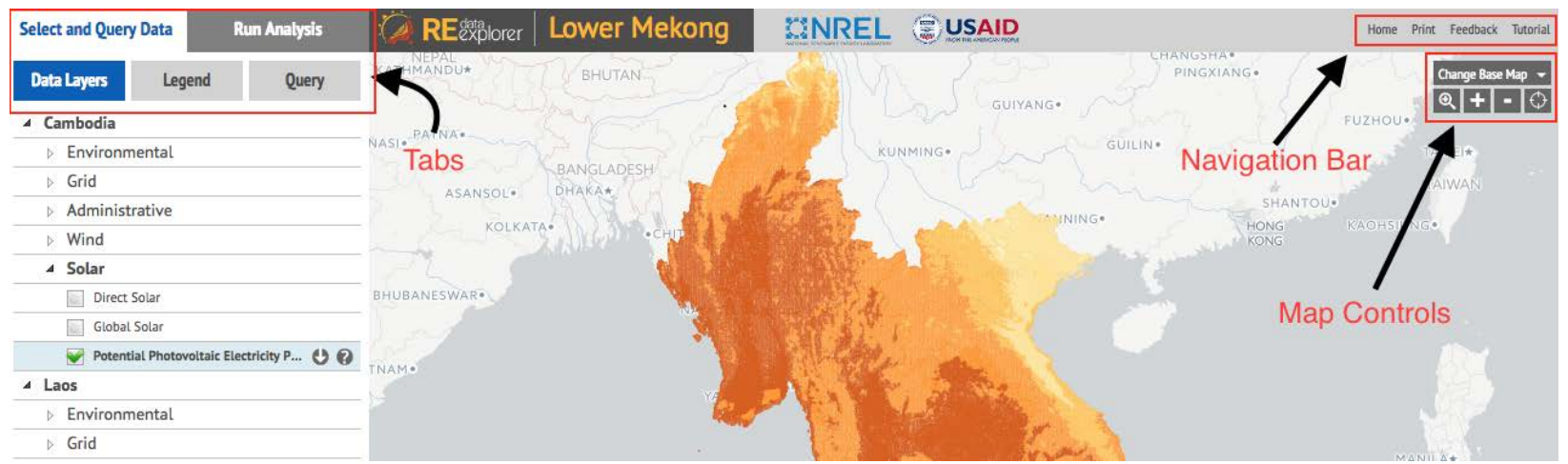




\subsubsection{Map Controls}

Change base $\operatorname{map} \longrightarrow$ Change Base Map $~$
Zoom to extent $\longrightarrow$ Q + -

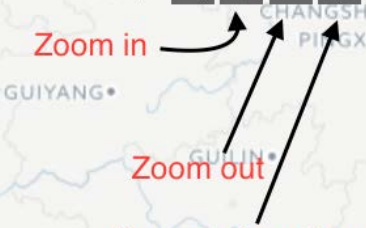

Zoom to Location
With the map controls in the upper right of the map, users can (1) change the base map, (2) zoom in and out, (3) zoom to select a specific "extent" or bounded area, or (4) zoom to an exact location (e.g., latitude and longitude).

- Change base map: Click Change Base Map to open a pull-down list. The user can then select a base map to view. The options are OpenStreetMap, Google Hybrid, Google Terrain, Google Satellite, Google Roadmap, CARTO Dark, and CARTO Light. The choice of a base map will not impact the data layer visualization or analysis capabilities in the RE Data Explorer.

Change Base Map None

OpenStreetMap Google Hybrid Google Terrain Google Satellite Google Roadmap CARTO Dark CARTO Light

- Zoom to extent: First, click the magnifying glass. Then, click and hold the magnifying glass [ Q ] on the map to create one corner of a rectangular area. While still holding the mouse, drag it to select the opposite corner of a rectangle. When the mouse is released, the map will zoom in to the boundaries of the rectangle just drawn.

- Zoom to location: Click the target [ 0 ] and type an address, city, state, zip code, country, or a set of coordinates into the dialogue box to zoom in on a specific location.

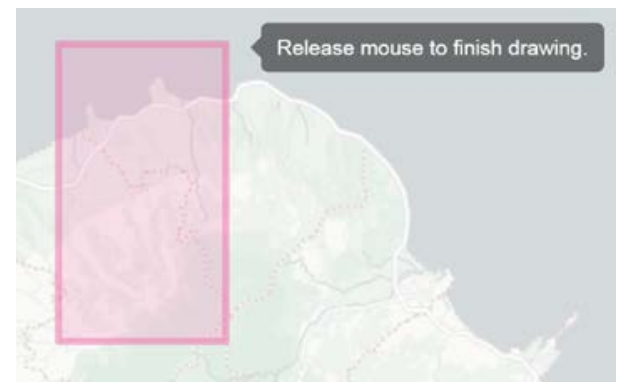

Find Location

Enter an address, city, state, zip, or Lat/Long

Users can also click, hold, and drag any point on the map 


\subsubsection{Select and Query Data Tab}

Use the Select and Query Data tab in the upper left of the RE Data Explorer to (1) select which data layers to display on the map, (2) customize the map display by modifying the legend, or (3) perform queries by a user-selected region or area.

\begin{tabular}{|l|l|l|}
\hline Select and Query Data & \multicolumn{2}{|c|}{ Analysis \& Downloads } \\
\hline Data Layers & Legend & Query \\
\hline
\end{tabular}

\section{Data Layers}

Use the Data Layers tab to view a list of all data layers for a country and select which ones to display on the map. Available spatial layers are organized into categories-renewable resource type, grid components (e.g., transmission lines), environmental variables (e.g., land use), and administrative layers (e.g., country boundaries) —in an expandable and collapsible layer "tree."

- Expand and collapse categories: Click the triangle icon to the left of a category to expand (show) or collapse (hide) the list of all data layers within the category.

- Turn layers on and off: Click on a layer name or the

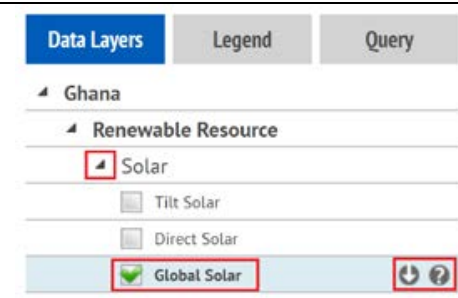
checkbox to turn a layer on and off. Data layers that are checked will be displayed on the map and will be included in queries.

- Download a layer: Click the down arrow icon to the right of a layer name to download the layer in CSV, Shapefile, KML, or GeoJSON format. Certain layers are not available for download because of licensing restrictions or size limitations.

- View metadata: Click the question mark icon to the right of a layer name to view the metadata (i.e., documentation) for the layer.

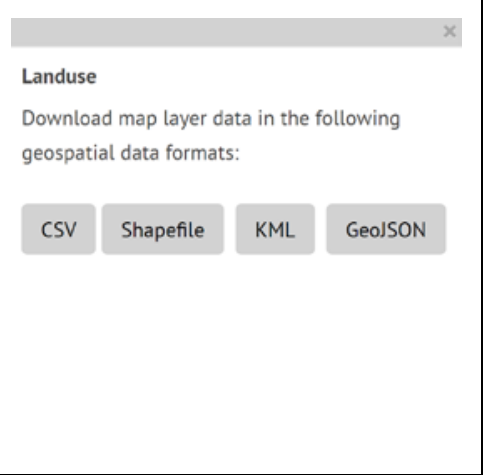




\section{Legend}

Use the Legend tab to view and adjust the legend for the layers selected.

- Select categories: Some data layers organize information into multiple categories (e.g., different types of land use or different ranges of solar or wind resources). In the legend, all categories in a layer are displayed by default. To turn off a category within a layer (e.g., Forest within Land Use), uncheck the box next to the category. To restore an unchecked category, simply check the box next to it.

- Change layer order: Click the up or down arrows to the right of the layer name to move that layer above or below another layer.

- Transparency: Move the transparency slider to increase or decrease the transparency of a layer. With $0 \%$ transparency, the data layer will be at the greatest level of visibility and may cover other layers. With $100 \%$ transparency, the data layer will no longer be visible. If one layer is hidden under another, users can change layer transparency to make more than one layer visible. For example, if a solar layer is hidden under a wind layer, changing the wind layer transparency to $50 \%$ can make both layers visible.

\section{Query}

A query is a request for a subset of data from a larger data set. In the RE Data Explorer, a user can run a query for specific geographic areas. A user can query the active or selected data layer for a single point, for a rectangular region selected, for a custom shape that is draw, or by attributes of the data. The four mutually exclusive options are listed in panels under the Query tab.

\begin{tabular}{l}
\hline Data Layers Legend \\
\hline $\begin{array}{l}\text { Point Query } \\
\text { Select a single point on the map and get } \\
\text { data for that location. }\end{array}$ \\
\hline $\begin{array}{l}\text { Region Query } \\
\text { Select an area on the map and get data for } \\
\text { that area. }\end{array}$ \\
\hline $\begin{array}{l}\text { Custom Shape Query } \\
\text { Draw a custom shape on the map and view } \\
\text { data for that area. }\end{array}$ \\
$\begin{array}{l}\text { Attribute Query } \\
\text { Use this advanced feature to filter your } \\
\text { query based on specific attributes. }\end{array}$ \\
\hline
\end{tabular}


- Point Query (the default query): Click on a point ${ }^{2}$ on the map to see attributes of the data for several pixels near the point selected.

Data will be returned for all active layers and data. Use the triangle icon to the left of an individual result to view the values for that result.

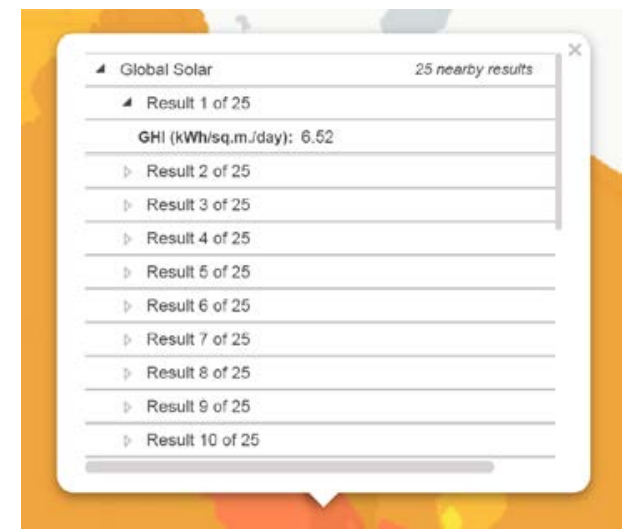

- Region Query: First, click the Region Query panel. Then, click and hold the mouse on the map to create one corner of a rectangular area. While still holding the mouse, drag it to select the opposite corner of a rectangle. When the mouse is released, the user will have selected a rectangular area and created a query of all active layers and data. This allows a user to chart the data and download a CSV file without spatial information included.

To view data for different layers, click the tabs in the results window.

If the data are available for download, a user can download the results by clicking Download Query Results in the top right corner of the results pane. If no data are available for download, this option will not appear.

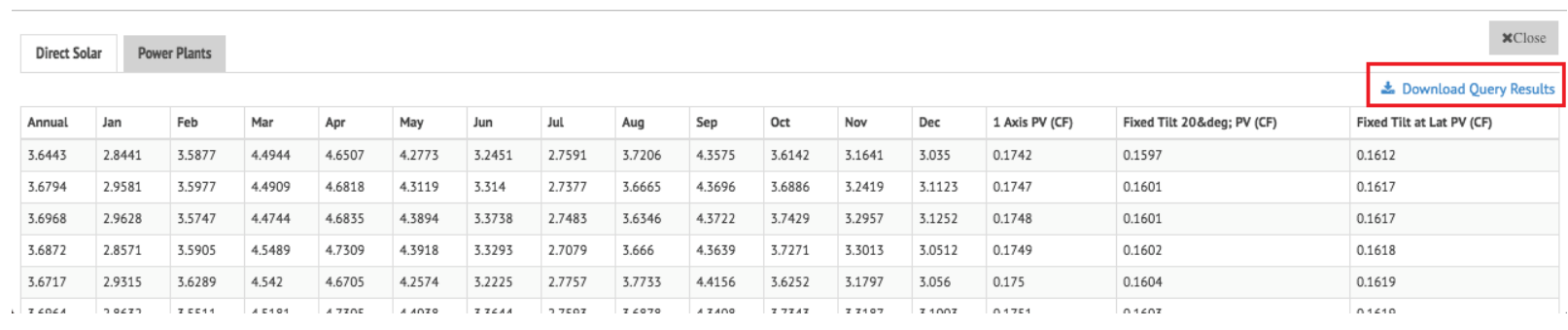

\footnotetext{
${ }^{2} \mathrm{~A}$ point on the screen, a pixel, represents a polygon-shaped geographical area, instead of a precise point. When a user does a point query, they click on a pixel. Depending on the current zoom level, the amount of geographic space the pixel represents changes. Since pixels are not representative of very precise points in real space, when users do a point query, a buffer is placed around the pixel that was clicked on. Data are returned for all pixels within this buffer, and thus multiple results are returned for a point query. Even if a pixel is noted to have only one value, multiple results are still returned as the buffer may include wider areas of geographic space with differing values than the point clicked on. The size of the buffer also changes in relation to zoom level.
} 
- Custom Shape Query: First, click the Custom Shape Query panel, then draw a polygon on the map by clicking to drop points on the map, which will automatically be connected to form a polygon. Click the beginning point to close the polygon.

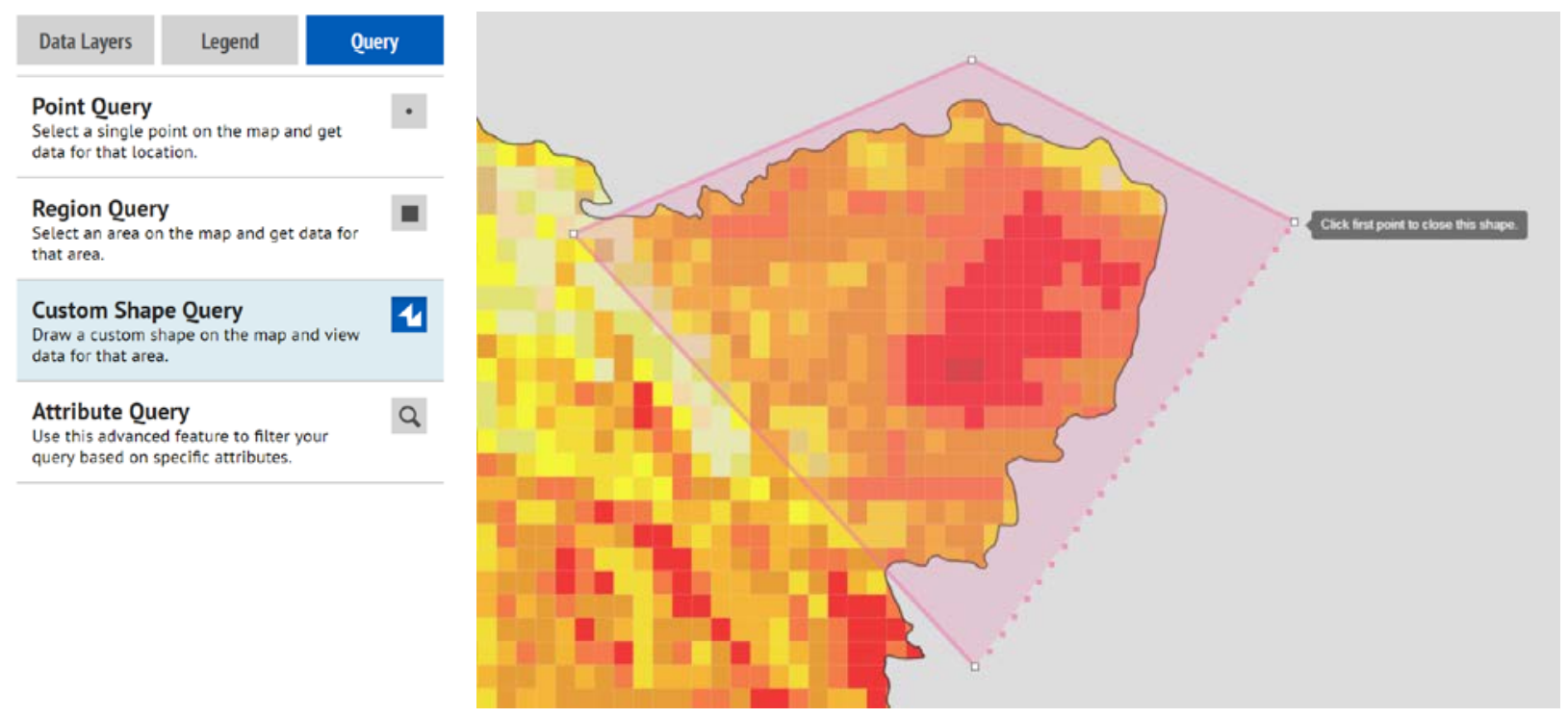

Results for custom shape queries are displayed in the same way as results for region query.

Attribute Query: Attributes are features of the data such as wind speed or potential solar photovoltaic (PV) electricity production. Data layers often have more than one attribute, such as elevation, which has attributes of elevation in meters and percent slope. An attribute query allows users to perform a query based on certain features and values of the active or selected data. Begin by clicking the Attribute Query panel (shown on the next page). To run an attribute query:

1. Select the layers to query: Visible Layers or All Layers.

2. From the pull-down list, next to Visible Layers or All Layers, select the Attribute to query (e.g., Potential Photovoltaic Electricity Production).

3. From the pull-down list, select an Attribute Name. Then, select an Operator (e.g., all results greater than, less than, or equal to the value). Then enter a numeric Value.

For Condition, select End if the preferred option is to query only one attribute and value. To query results based on a second attribute or value, select either Or or And to specify a condition. Users can create a combination of queries by repeating this step and selecting End when they are done.

4. Click Execute to run the query.

Or, click Reset to reset the query form.

Or, click Cancel to leave the attribute query. 


\section{Query by Attribute}

\begin{tabular}{|l|l|}
\hline Select a Layer & \multicolumn{2}{|l|}{$\mid$} \\
\hline \begin{tabular}{ll}
\hline Visible Layers \\
All Layers
\end{tabular} & Please select a layer \\
\cline { 2 - 2 } & Please select a layer to query. Then construct a set of filters using the form below. \\
\hline
\end{tabular}

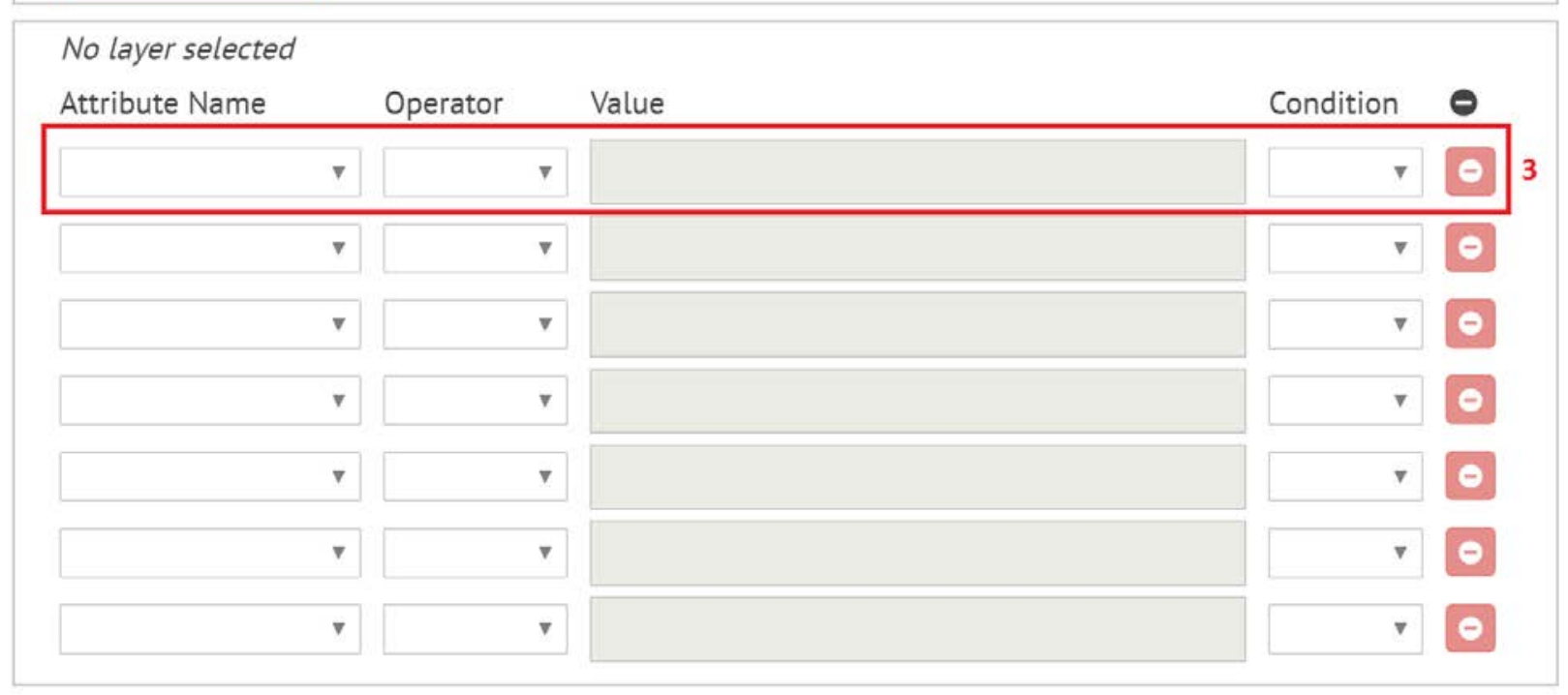

\begin{tabular}{|l|l|l|}
\hline Execute & Reset & Cancel \\
\hline
\end{tabular}

Potential Photowoltaic Electricity Production

PVout (kWh/kWp/day)

4.015999794006348

4.02400016784668

4.038000106811523

4043000221252441

4.046000003814697

This report is available at no cost from the National Renewable Energy Laboratory at www.nrel.gov/publications. 


\subsubsection{Navigation Bar}

The navigation bar-in the top right of the RE Data Explorer-provides five options:

About Home Print Feedback Tutorials

- About: Click About for information on the GIS infrastructure and disclaimers for the RE Data Explorer.

- Home: Click Home to reset the map view to the default settings.

- Print: Click Print to print the current map view. Users can also use this option to:

o Download the current view of the map, including all layers currently shown and separate legends and map overlays

o Style the footer text for the map using HTML.

- Feedback: Click Feedback to open a text box and send feedback to the RE Data Explorer development team.

- Tutorial: Click Tutorial to take one of two guided tutorials:

o The GIS Functionality tutorial covers:

- Navigating the map

- Viewing spatial layers

- Downloading spatial data

- Querying spatial data using the point, area, or custom shape query.

o The Attribute Query tutorial shows the user how to query for data filtered by certain values of the data's properties.

\subsection{Analysis and Downloads}

\subsubsection{Time Series Data Download Tool}

Renewable energy resource data varies temporally as the resource amount changes throughout the day, month, and year as well as from one year to another, which is called interannual variability (see Text Box 1). For some countries in the RE Data Explorer, users can download temporal (also called time-series) data for solar or wind. Because these data sets are often very large, the Time Series Data Download tool must be used to download these data.

In the RE Data Explorer, time series data download functionality is available for certain countries where time series data are available. When this user guide was published, time series wind data were available for the Philippines and were expected to soon be available for India. Time-series solar and meteorological data are available for Afghanistan (eastern part), Bangladesh, India, Nepal, and Mexico through integration of NREL's National Solar Radiation Database (NSRDB). ${ }^{3}$ Time series data and related download functionality will be available for other countries in the RE Data Explorer over time.

\footnotetext{
${ }^{3}$ Users can learn more about these data and how they were modeled at "National Solar Radiation Database (NSRDB),” nsrdb.nrel.gov.
} 


\section{Text Box 1. The Temporal Aspects of a Data Set}

Source: Cox et al. 2018

Understanding the temporal aspects of a data set and differing time characteristics is critical for analysts as they consider how the data can be to inform decisions.

Key temporal characteristics of data sets include:

- Sample interval: the rate of a sample-e.g., $1 \mathrm{~min}, 15 \mathrm{~min}$, hourly, daily, or annual

o Instantaneous or integrated

o Instantaneous can be thought of as a snapshot of the resource value at a specified time.

- Integrated data generally represent the entire range of a specified time interval (e.g., an hour), which is similar to an instantaneous midpoint value of a specified time interval.

- Intervals: the sample clock time representation-e.g., whether an integrated sample taken at 3 p.m. represents 2 p.m. -3 p.m. or 3 p.m.4 p.m.

- Various combinations of the above

- Temporal range: typically defined as years of coverage or period of record. For example, hourly data for 2005-2010 is five years of hourly data. Having multiple years of data is important to understanding the interannual variability of a given resource.

These temporal characteristics of data sets become very important for certain types of modeling. For example, if an analyst is looking at ramp rates for energy reserves in a reserves analysis, results might vary between instantaneous or integrated data sets. In this case, and in others, awareness of the temporal components of a data set becomes very important to the modelers and decision makers who depend on the results.

For more information on temporal data and other data to support renewable energy analysis and decisions, see Cox et al. (2018). 
Analysis \& Downloads Tab/Downloads Tab: To view the options for downloading data, click either the Analysis \& Downloads tab (shown at top right) or the Downloads tab (shown at bottom right). ${ }^{4}$ Then, either (1) download data by point selecting that option and clicking on the map or (2) selecting the Box option (e.g., Solar Time Series Data Download [Box]) and then drawing an area on the map. Previous instructions for drawing a Box are included in the section describing query functionality under Region Query.

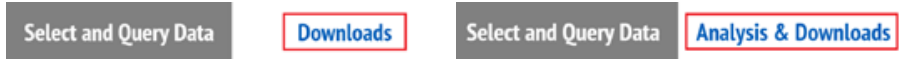

Data Download Information Form: Once the user has selected the area for which they would like to download data, they will be asked to enter their Full Name, Email, Organization/Affiliation, and Planned Use for the data in a Data Download Information Form. This information (at the aggregate level) will help NREL better understand the impact and uses of the RE Data Explorer so it can be improved over time. If users include their email addresses in the Information Form, they are also added to the RE Data Explorer and/or NSRDB (depending on the data source) mailing lists.

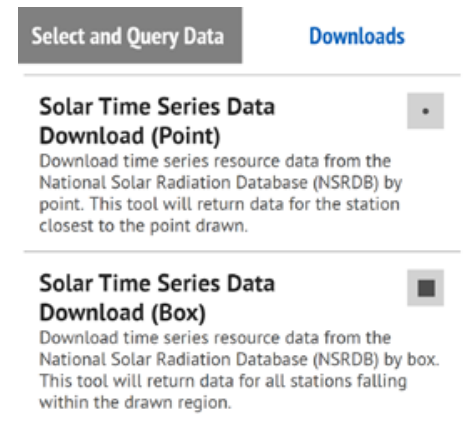

Data Download Wizard: After the user has completed the Data Download Information Form, the Data Download Wizard will appear, with a description of the data set provided in the left panel of the wizard.

On the right side of the Data Download Wizard (shown on the next page), the user must select the year for which they would like to download data. Then, the user may select (1) the attributes they would like to download and (2) their download options (i.e., Include Leap Day and/or Convert UTC to Local Time). If the Download Limit Indicator at the bottom of the wizard is red, the user must deselect some selected values.

When the user has finished selecting the years and attributes they want to download, they can click Download Data. An email will be sent to the user with the link to download the requested data files. It can take between a few minutes to a few hours for the download to be prepared and delivered. The data will be delivered in a zip file with a CSV file enclosed.

\footnotetext{
${ }^{4}$ Certain tools that only have download functionality only have a Downloads tab. Others that also offer analysiscovered later in this guide- have an Analysis \& Downloads tab.
} 


\section{Data Download Wizard}

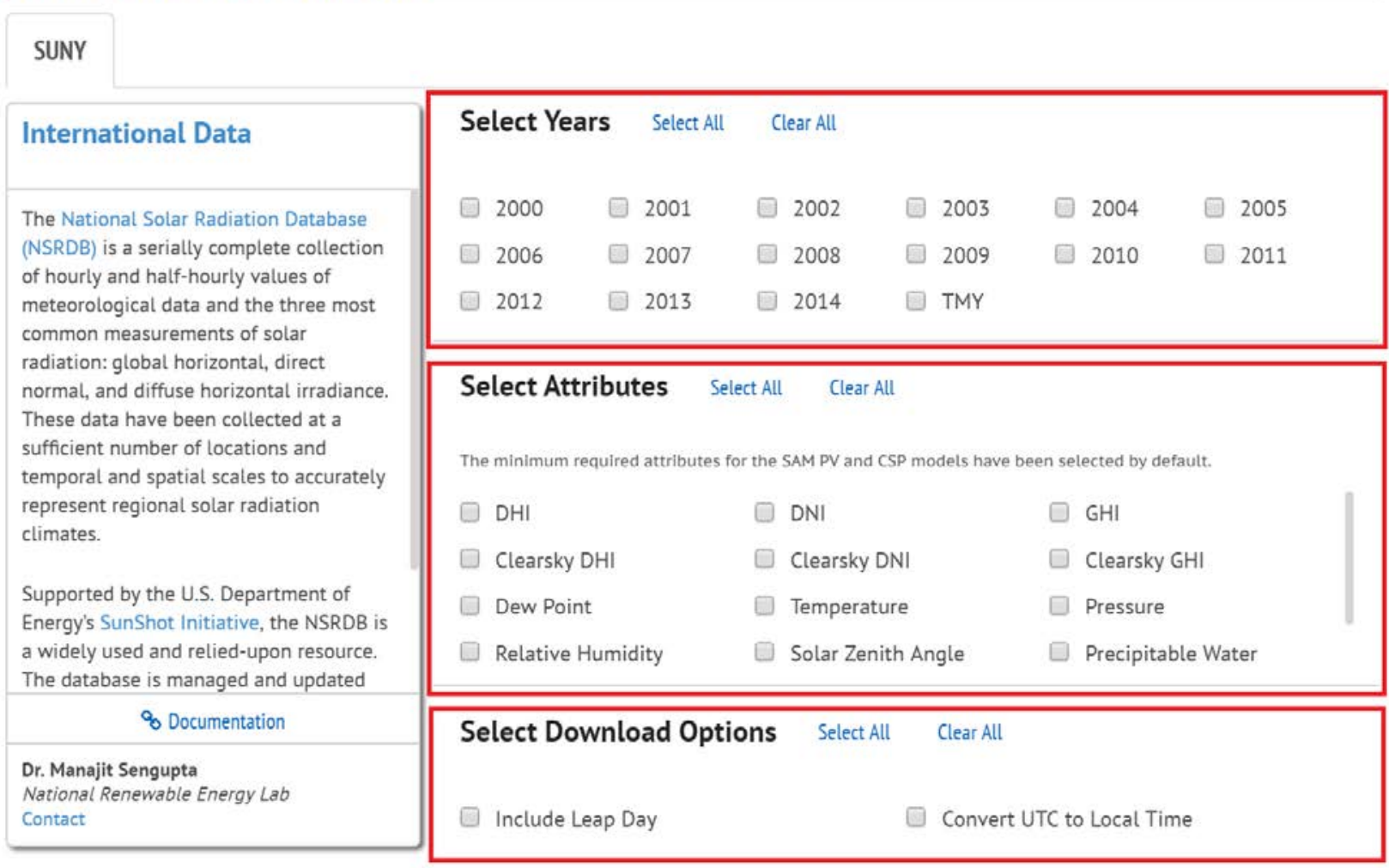




\subsubsection{Technical Potential Tool}

The technical potential of a renewable energy technology is its achievable energy generation given system performance and topographical, environmental, and land-use constraints. When assessing a parcel of land for technical potential, one must consider that not all areas of land are viable for building solar arrays, wind turbines, geothermal power plants, or other advanced or conventional sources of electricity generation. A technical potential analysis provides an upperboundary estimate of renewable energy development potential in a particular area (Lopez et al. 2012).

Technical potential analysis is one of several approaches to evaluate renewable energy resource potential. As described above and presented in Figure 1, technical potential analysis builds on resource potential and accounts for system and topographic constraints, land-use constraints and system performance. Further analysis can also build on technical potential to evaluate renewable energy potential in relation to costs and other economic and market considerations, as highlighted in Figure 1. The figure provides information on what is included within resource, technical, economic and market potential analyses, which are ordered from least complex to most complex. The RE Data Explorer provides tools to support technical potential analysis in several countries. And, capabilities are also being developed to support economic potential analysis in certain regions and countries. This section of the user guide focuses on technical potential analysis.

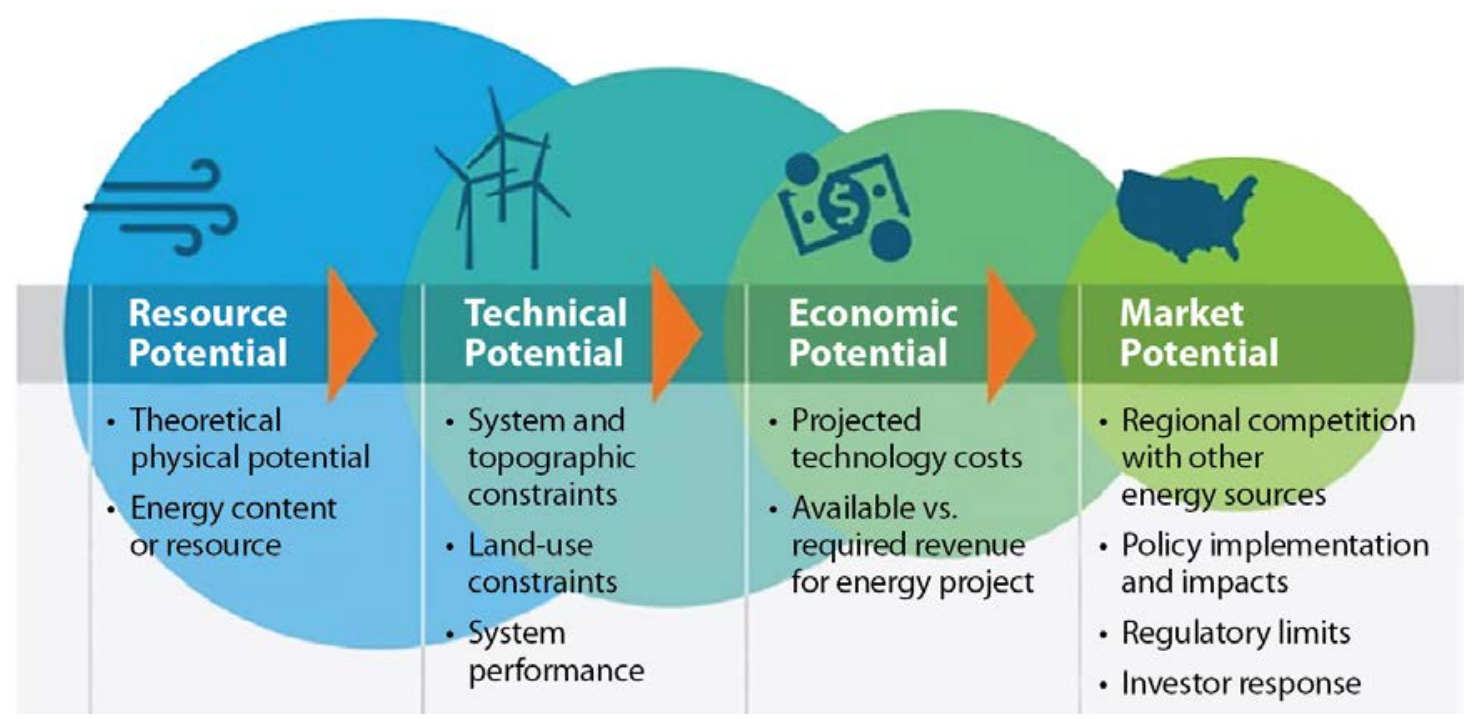

Figure 1. Resource, technical, economic, and market potential of renewable energy

Source: Brown et al. 2016 


\section{How to Use the Technical Potential Tool}

Rum Analysis or Analysis \& Downloads Tab ${ }^{5}$ : Click the Run Analysis or Analysis

\& Downloads tab. Then click on Technical Potential to launch the Technical Potential tool, and the Technical Potential tool analysis box below will open.

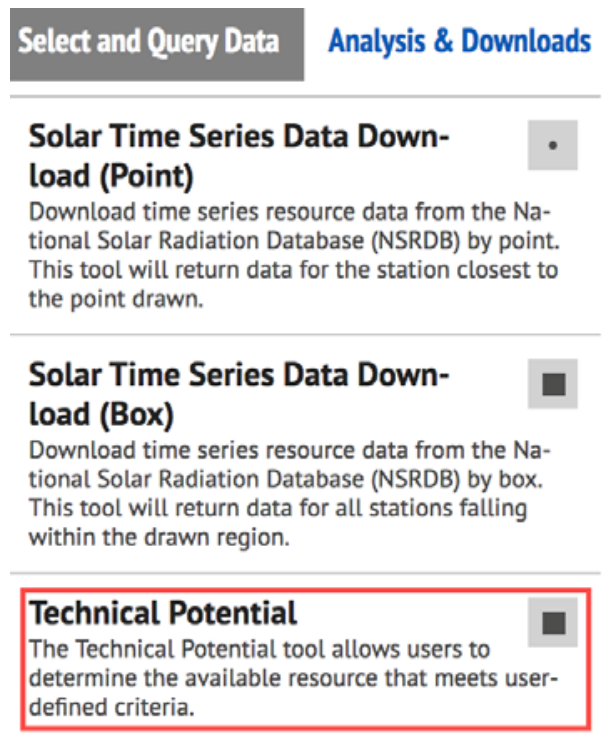

Technical Potential Tool: To run a technical potential analysis:

1. Choose region (e.g., a province) or country of interest from the left panel of the tool.

2. Select a resource (solar or wind) and technology types from the pull-down lists in the second panel from the left. Technology types in the RE Data Explorer are described below.

o Fixed-tilt PV is an array that is tilted at a fixed angle based on local latitude, structure orientation, and electrical load requirements to maximize solar resource utilization. ${ }^{6} \mathrm{PV}$ technology uses photons coming from sunlight irrespective of direction. Global Horizontal Irradiance (GHI), or the sum of direct and diffuse solar radiation, is used to understand fixed-tilt PV generation potential. (NREL 2016). For details on the land-use assumptions for fixed-tilt PV used in the Technical Potential tool, see Ong et al. (2013).

o Concentrating solar power (CSP) uses linear concentrator systems that "collect the sun's energy using long rectangular, curved (U-shaped) mirrors. The mirrors are tilted toward the sun, focusing sunlight on tubes (or receivers) that run the length of the mirrors. The reflected sunlight heats a fluid flowing through the tubes. The hot fluid then is used to boil water in a conventional steam-turbine

\footnotetext{
${ }^{5}$ Depending on data download functionality certain tools have a "Run Analysis" tab (without data download functionality) and others have an "Analysis and Downloads" tab. Please note that in the screenshot, the "Analysis and Downloads" functionality is pictured rathen that the "Run Analysis" functionality.

6 "Solar Photovoltaic System Design Basics," U.S. Department of Energy's Office of Energy Efficiency and Renewable Energy, August 20, 2013 , https://www.energy.gov/eere/solar/articles/solar-photovoltaic-system-designbasics.
} 
generator to produce electricity”. 7 "Direct Normal Irradiance (DNI), also referred to as beam irradiance, is the direct sunlight that falls on a CSP mirror or collector surface. This direct beam can then be concentrated onto a receiver, which collects the energy" for concentrating solar power (NREL 2016). Thus, DNI solar data is most useful for CSP. For details on the land-use assumptions for CSP used in the Technical Potential tool, see Ong et al. (2013).

o Wind turbines are mounted on towers and use wind to turn the blades mounted on a shaft (called the rotor) and produce power. Wind data are modeled at 100-m hub height (rotor's height above ground) for different turbine characteristics in the RE Data Explorer. It is recommended that users select a turbine type based on annual average wind speed. The 2015 Cost of Wind Energy Review (Mone et al. 2017, Table 12, page 23) provides guidance on selecting a turbine type (T200, T237, etc.), where the average annual wind speed corresponds to the following:

T200: $<=5.5 \mathrm{~m} / \mathrm{s}$

T237: $7.4 \mathrm{~m} / \mathrm{s}$

T245: $8.0 \mathrm{~m} / \mathrm{s}$

T255: $8.4 \mathrm{~m} / \mathrm{s}$

T325: >=10.0 m/s

3. Apply limits to the resource or its proximity to infrastructure (third panel). For example, assigning the value of 10 kilometers to Limit by Distance to Roads means the results will include only areas within $10 \mathrm{~km}$ of the nearest road, based on the Roads data layer in the RE Data Explorer for a particular country.

4. Exclude restricted or sensitive areas of land or limit by slope in the fourth panel.

See Section 2 to learn about using limits (Step 3) and exclusions (Step 4) to focus an analysis. Section 3 provides information on technical potential results.

7 “Concentrating Solar Power Basics,” NREL, https://www.nrel.gov/workingwithus/re-csp.html 


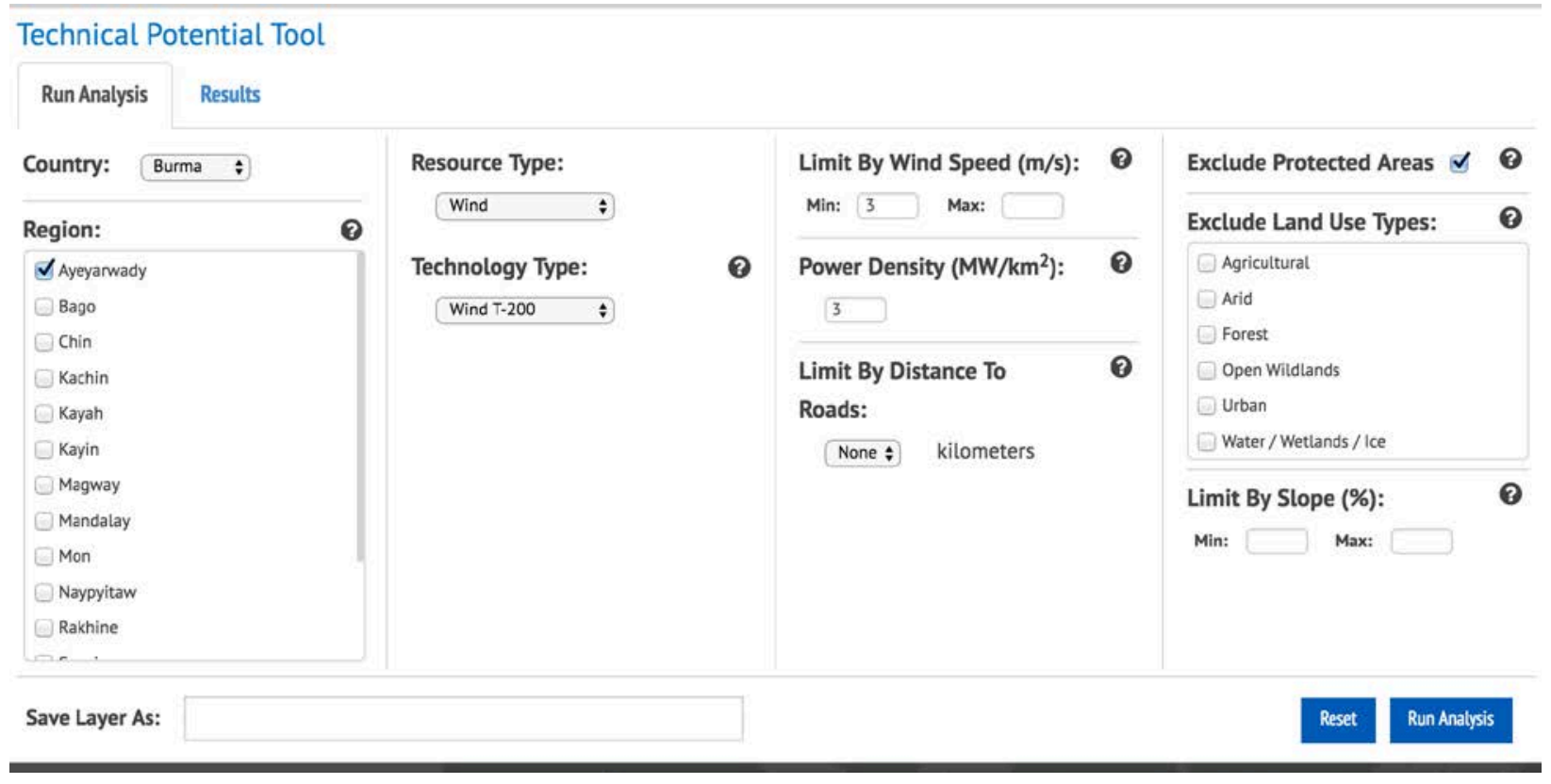




\section{Technical Potential Tool: Using Limits and Exclusions to Create Scenarios}

Using the Technical Potential tool in the RE Data Explorer, a user can use limits and exclusions to create different scenarios that account for technical constraints that might impact the development of solar and wind resources.

A technical potential scenario includes a pre-defined set of assumptions, including limits and exclusions, that define the RE resources and land areas that are technically feasible for development. Scenario definition can have a major impact on the estimation of technical potential. Figure 2 (next page) illustrates three examples of technical potential scenarios for fixed-tilt solar photovoltaic (PV) energy in Vietnam using the RE Data Explorer. Depending on the scenario definition, the generation potential ranges from 847 million MWh/year in the most restrictive case (Scenario 3) to 12 billion $\mathrm{MWh} /$ year in the least restrictive case (Scenario 1).

The definition of technical potential scenarios should be driven by the technical constraints (limits and exclusions in the RE Data Explorer) that are most likely to impact the development of solar PV and wind power plants in a country or region. For example, in some countries, developing wind projects on agricultural land may be difficult due to local policy and regulations protecting food production; while in other countries, wind might be a valued economic proposition to support agricultural communities with guaranteed leasing income. Defining multiple scenarios that evaluate technical potential including and excluding agricultural lands may be valuable for these countries. In other countries, terrain (i.e., slope) may be a more important driver of project development influencing land access, so including scenarios that vary this parameter may be most important.

The sections below describe limits and exclusions that can be used in the Technical Potential tool. 


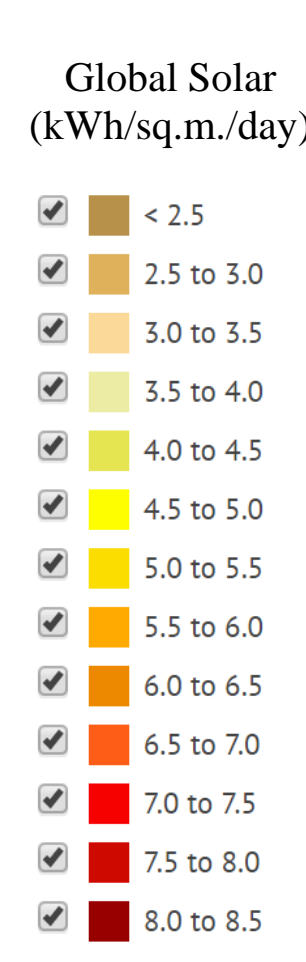

Scenario 1

- Designated protected areas

- Water, wetlands, and ice

\section{Results}

- $273,231 \mathrm{~km}^{2}$ total land area

- 12 billion MWh/yr AC generation potential
Scenario 2

- Designated protected areas

- Water, wetlands and ice; and urban areas

- Lands with slope exceeding $5 \%$

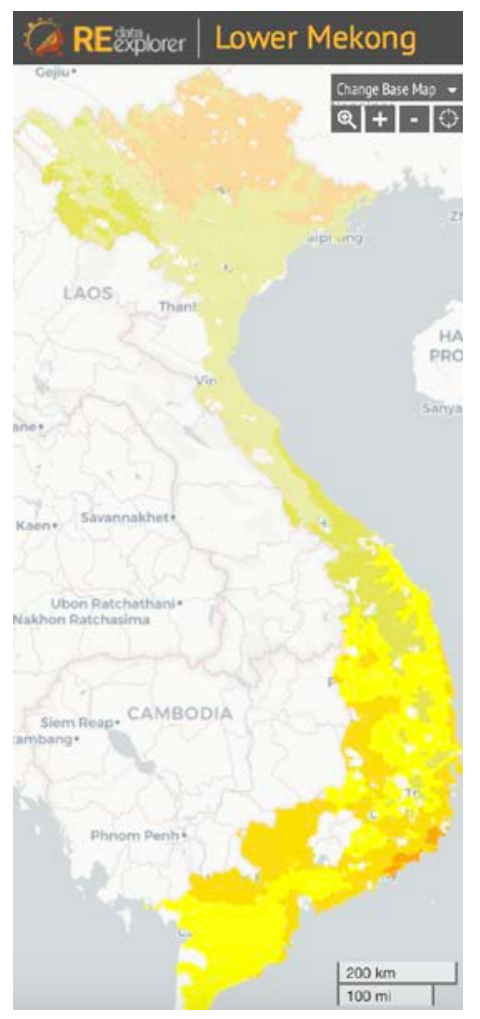

Te REexplorer | Lower Mekong

caluc

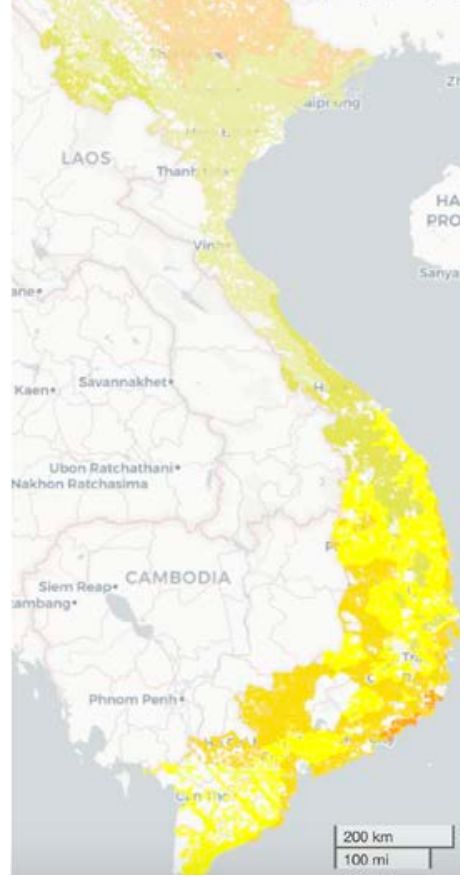

Scenario 3

- Designated protected areas

- Water, wetlands and ice; and urban areas; agricultural lands; and forest lands

- Lands with slope exceeding $3 \%$

- $18,441 \mathrm{~km}^{2}$ total land area

- 847 million MWh/yr AC generation potential

Figure 1. Three examples of technical potential scenarios for fixed-tilt solar PV in Vietnam Source: RE Data Explorer

\subsection{Limit Results by Resource}

Limiting by resource ensures the technical potential analysis results include only areas that are above or below a solar or wind resource threshold specified by the user. 
Solar results are limited by the solar intensity specified in kilowatt-hours per square meter per day (kWh/m2/day) GHI for PV (single-axis tracking and fixed-tilt) and DNI for CSP. The threshold for wind is based on wind speed (meters per second).

By default, for solar analysis, the Limit by Solar Resource field ranges from 2 to $9 \mathrm{kWh} / \mathrm{m} 2 / \mathrm{day}$, which provides a typical lower and upper bound threshold for solar resource potential in various locations. The minimum threshold default value of $2 \mathrm{kWh} / \mathrm{m} 2 /$ day is provided in the Technical Potential tool to exclude areas of land that have low resource availability. Typically, areas of 2 or fewer $\mathrm{kWh} / \mathrm{m} 2 /$ day of solar resource potential are unlikely to produce enough electricity to be feasible for new solar development. ${ }^{8}$ However, the user can override the default minimum (and maximum) values for solar resource potential in the tool based on local knowledge and circumstances.

For wind technical potential analysis, a minimum default value of $3 \mathrm{~m} / \mathrm{s}$ wind speed is included in the Technical Potential tool. This is to denote that areas with wind speeds lower than $3 \mathrm{~m} / \mathrm{s}$ are often considered unviable for wind project development, but as technology changes, areas with low wind speed may become more viable. The user can override this default value and input any wind speed based on local knowledge and circumstances.

\subsection{Limit Results by Power Density}

Power density represents the amount of capacity that can be reasonably expected from a given unit of land for a technology. Power density accounts for factors such as panel and turbine spacing and access to roads. Power density applies a nameplate capacity ${ }^{9}$ for a unit of land, and it is represented in terms of megawatts per square kilometer $\left(\mathrm{MW} / \mathrm{km}^{2}\right)$. For solar technologies, the power density tends to be around $30-36 \mathrm{MW} / \mathrm{km}^{2}$, while for wind it is much lower at $3 \mathrm{MW} / \mathrm{km}^{2}$. The difference between PV and wind power densities is because PV panels can be placed close together while wind turbines require larger swaths of land and greater spacing.

Power density is a subjective metric, and it is likely to vary by location and to change as technology advances. Several studies for the United States have determined general power densities for PV, CSP, and onshore wind, but these act only as guidelines. To determine the power density for a given location, analysis should be conducted locally to determine the realistic power density for the areas of focus. Additional information can be found in:

- Land-use Requirements for Solar Power Plants in the United States (Ong et al. 2013) examines the area required for PV systems of various configurations and sizes.

- U.S. Renewable Energy Technical Potentials: A GIS-Based Analysis (Lopez et al. 2012) discusses the power densities for various technologies.

- Estimating Renewable Energy Economic Potential in the United States: Methodology and Initial Results (Brown et al. 2016) updates the power densities assumed in Lopez et al. (2012),

\footnotetext{
${ }^{8}$ Setting a maximum resource threshold is not likely very attractive for users wanting to find the best locations for new projects, but this option is made available nonetheless. Users can set a maximum resource threshold if they want to find different classes of resource availability, but in most cases, a maximum resource threshold does not need to be set.

${ }^{9}$ Nameplate capacity refers to the average capacity for each technology type that can be built in a square kilometer of land.
} 
and in the case of wind, reduces the assumption of $5 \mathrm{MW} / \mathrm{km}^{2}$ to $3 \mathrm{MW} / \mathrm{km}^{2}$, based on input from the wind industry.

\subsection{Limit Results by Proximity (to Roads and Transmission)}

Limiting by proximity allows a user to ensure available land areas resulting from the technical potential analysis are within a preset distance to roads or transmission lines, two major infrastructure features whose proximity can impact project viability and costs. Limiting by distance to infrastructure such as roads and transmission lines starts to bridge the gap between technical potential and economic potential, as new projects built closer to roads and transmission lines would likely be less expensive and would be expected to be connected to the grid. Based on local data availability and for certain countries, the RE Data Explorer has options to limit technical potential results in relation to both road and transmission infrastructure. For other countries, the RE Data Explorer includes only data on roads and so does not have the option to limit results in relation to transmission infrastructure.

\subsection{Exclude Protected Areas}

Protected areas are another input available for exclusion in the Technical Potential tool. If a user clicks on Exclude Protected Areas, the technical potential analysis will exclude national parks, culturally significant areas, and other sensitive areas of land from the results.

\subsection{Exclude Results for Land Cover/Land Use}

Limiting by land cover/land use allows the user to exclude areas that are either unfeasible to develop or may be negatively affected by the development of new solar or wind generators. For example, a solar technical potential analysis that excludes croplands could help ensure food security is not impacted by new solar development; however, a wind technical potential analysis for the same area might not exclude croplands because wind turbines are generally more compatible with agriculture than solar panels.

Along with categories including croplands, forests, or water bodies, urban areas can be included or excluded depending on the kind of systems the user is considering for development. Excluding urban areas would ensure only places that are suitable for large utility-scale solar or wind projects are available. Wind turbines generally will not be developed within urban areas, but distributed PV systems can be located in green spaces within urban boundaries.

\subsection{Limit by Slope (\%)}

Limiting by topography ensures areas located on steep slopes that would be either technically unfeasible or otherwise too expensive for renewable energy development are excluded from the technical potential results. The following are rules of thumb, particularly for U.S. analyses:

- For PV installations such as fixed-at-latitude and single-axis tracking systems, slopes of 5\% or greater are usually excluded from consideration (Brown et al. 2016).

- For CSP, even flatter land is normally needed, with slopes of $3 \%$ or greater usually being excluded

- For wind turbines, slopes at 20\% or greater are usually excluded (Lopez et al. 2012). 
These values are not included as defaults in the tool and users should use their own knowledge and local considerations to include values for slope limitation. Table 1 provides an overview of the parameters, guiding questions, and general recommendations for using certain limits and exclusions highlighted above to inform technical potential analysis in the RE Data Explorer.

Table 1. Guidance for Using Limits and Exclusions

\begin{tabular}{|c|c|}
\hline $\begin{array}{l}\text { Technical Potential } \\
\text { Scenario Inputs (Limits } \\
\text { and Exclusions) }\end{array}$ & Guiding Questions and Recommendations \\
\hline \multirow[t]{2}{*}{$\begin{array}{l}\text { Designated protected } \\
\text { areas }\end{array}$} & $\begin{array}{l}\text { Should nationally designated protected areas (e.g., national parks, } \\
\text { conservation areas) be included in or excluded from consideration for } \\
\text { renewable energy project development? }\end{array}$ \\
\hline & $\begin{array}{l}\text { Recommendation: Exclude protected areas generally, unless major } \\
\text { categories of protected lands are eligible for development of utility-scale } \\
\text { solar PV and/or wind projects }\end{array}$ \\
\hline \multirow[t]{8}{*}{ Land use types } & $\begin{array}{l}\text { Which of the following types of land uses should be considered for RE } \\
\text { project development: }\end{array}$ \\
\hline & - Agricultural land \\
\hline & - Arid land \\
\hline & - Forest \\
\hline & - Open Wildlands \\
\hline & - Urban areas \\
\hline & - Water/wetlands/ice. \\
\hline & $\begin{array}{l}\text { Recommendation: Exclude water/wetlands/ice generally, as utility-scale } \\
\text { solar PV and wind projects are not typically compatible with these land use } \\
\text { types; It is also recommended that urban areas be excluded for wind } \\
\text { project development. Other land use types (e.g., agricultural, forest) can } \\
\text { be excluded from more restrictive technical potential scenarios if project } \\
\text { development on these types of lands is particularly difficult due to policy, } \\
\text { regulatory, or land acquisition/access challenges. }\end{array}$ \\
\hline \multirow[t]{2}{*}{ Slope } & $\begin{array}{l}\text { What is the maximum slope that will be acceptable for project } \\
\text { development? }\end{array}$ \\
\hline & $\begin{array}{l}\text { NREL's default criteria for analyses in the United States are a maximum } \\
\text { slope of } 5 \% \text { for utility-scale solar PV and a maximum slope of } 20 \% \text { for } \\
\text { utility-scale wind. }\end{array}$ \\
\hline \multirow[t]{2}{*}{$\begin{array}{l}\text { Urban development (solar } \\
\text { PV only) }\end{array}$} & $\begin{array}{l}\text { To what extent are sparsely developed urban areas (e.g., greenways) } \\
\text { available for solar PV development? }\end{array}$ \\
\hline & $\begin{array}{l}\text { NREL's default assumption is that urban and suburban areas that are } \\
\text { more than } 50 \% \text { developed (e.g., covered by buildings) are unavailable for } \\
\text { solar PV, but areas less than } 50 \% \text { developed are available. }\end{array}$ \\
\hline
\end{tabular}




\section{Technical Potential Tool: Understanding Analysis Results}

A technical potential analysis in the RE Data Explorer provides aggregated values for all provinces included in the analysis, as well as a breakdown for each individual province. Results include those described in this section. Results are also visually presented at the end of this section.

Total land area is the total available land remaining after all exclusions and limits are applied during the technical potential analysis. This is the value used to determine how much solar or wind capacity could be developed according to the inputs for a given analysis.

total land area $=$ total area $\left(\mathrm{km}^{2}\right)$ remaining after all exclusions and limits applied to the land

Nameplate capacity is the total installed solar or wind capacity that would result from full development of the total land area. This is the result of multiplying the power density value by the total land area:

nameplate capacity $(\mathrm{MW})=$ total land area $\left(\mathrm{km}^{2}\right)$ x power density $\left(\mathrm{MW} / \mathrm{km}^{2}\right)$

AC generation refers to the total annual generation that would result from the development of the full nameplate capacity of a selected technology. AC refers to alternating current, which is distinct from DC, or direct current. Results from the analysis are always in AC.

AC generation $(\mathrm{MWh} /$ year $)=$ nameplate Capacity $(\mathrm{MW}) \mathrm{x}$ generation potential (capacity factor) x 8,760 (hours per year)

Capacity factor is a measure of how much energy is produced by a plant compared with its maximum output. Capacity factor is measured as a percentage, generally by dividing the total energy produced during some period by the amount of energy the plant would have produced if it ran at full output during that time. Typical capacity factors for wind and solar PV in regions with good resources are about $30 \%-50 \%$ and $15 \%-20 \%$, respectively." ${ }^{10}$ Capacity factor values account for the efficiency of a technology, given considerations that might prevent it from generating at its full output over the course of the year. While capacity factor is not an output of the technical potential analysis in the RE Data Explorer, it is an important input to the calculation of AC generation results highlighted above. A user cannot manipulate the capacity factors used in the RE Data Explorer, as they are drawn from a spatially varying data set that underlies the spatial resource data within the model. For more information information on the resource analysis used to produce the capacity factors please see the Appendix.

capacity factor $=$ annual generation $(\mathrm{MWh}) /$ [nameplate capacity (MW) 8,760 (hours per year)]

10 “Glossary,” Greening the Grid Initiative, http://greeningthegrid.org/resources/glossary/glossary\#C 
Land area by resource bin is the total area in each resource range remaining after exclusions and limits are applied.

The following is an example of technical potential analysis visual map layer and quantitative results for Vietnam, based on inputs presented. Technical potential layers that are created can be downloaded by clicking the down arrow icon to the right of the layer's name and then choosing desired format options.

Technical Potential Tool

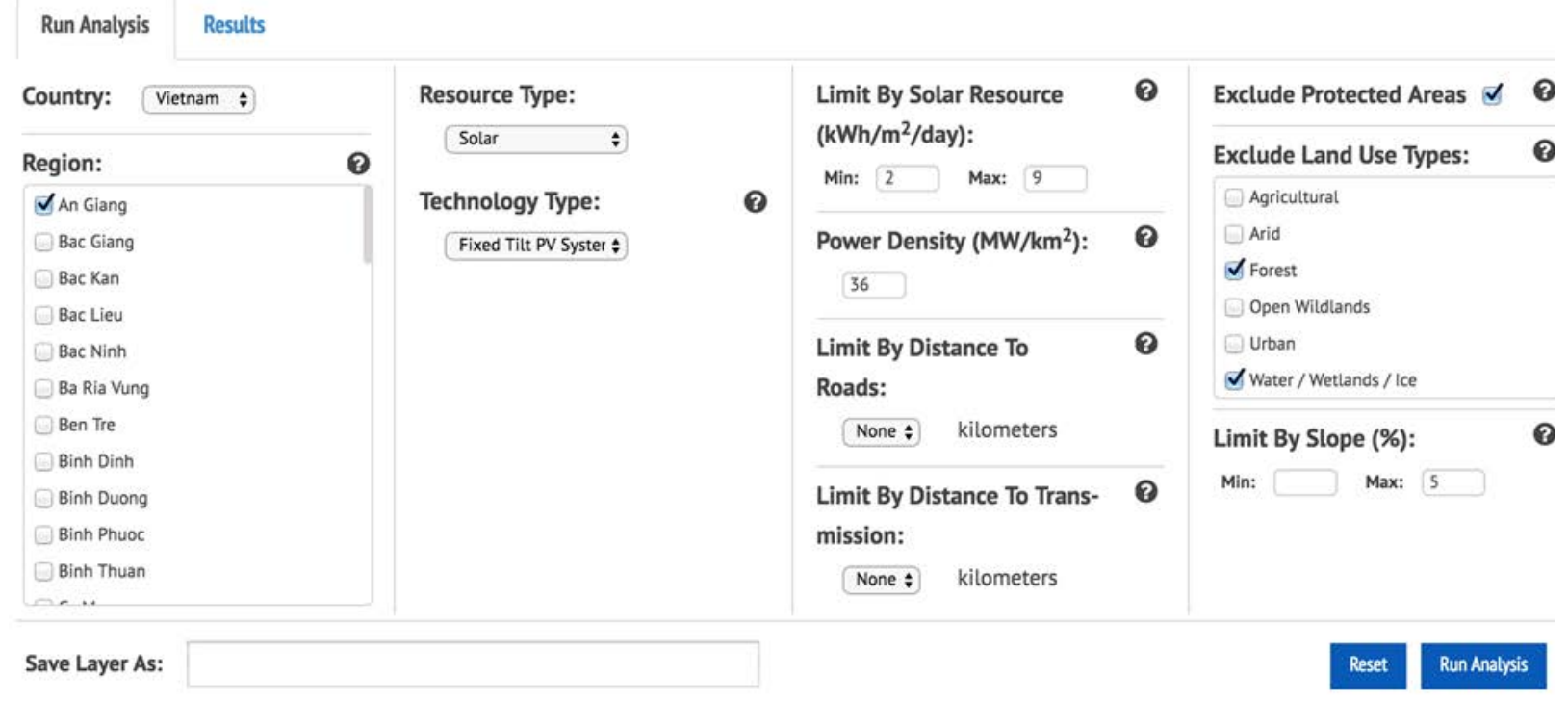

Technical Potential Tool

Run Analysis Results

Layer: Vietnam Fixed Tilt PV System 20-2-2018 13:11:41

Cumulative Results

AC Generation:

Total Land Area:

Nameplate Capacity:

Land Area by Resource Bin

$4.5-5 \mathrm{kWh} / \mathrm{m}^{2} / \mathrm{day}$ ?

5- $5.5 \mathrm{kWh} / \mathrm{m}^{2} /$ day:
166 million MWh/yr

$3,267 \mathrm{~km}^{2}$

$117,611 \mathrm{MW}$

$2,134 \mathrm{~km}^{2}$

$1,133 \mathrm{~km}^{2}$
Regional/State Results

\section{An Giang}

AC Generation:

Total Land Area:

Nameplate Capacity:

Land Area by Resource Bin

4.5- $5 \mathrm{kWh} / \mathrm{m}^{2} / \mathrm{day}$ :
166 million MWh/yr

$3,267 \mathrm{~km}^{2}$

$117,611 \mathrm{MW}$

$2,134 \mathrm{~km}^{2}$ 


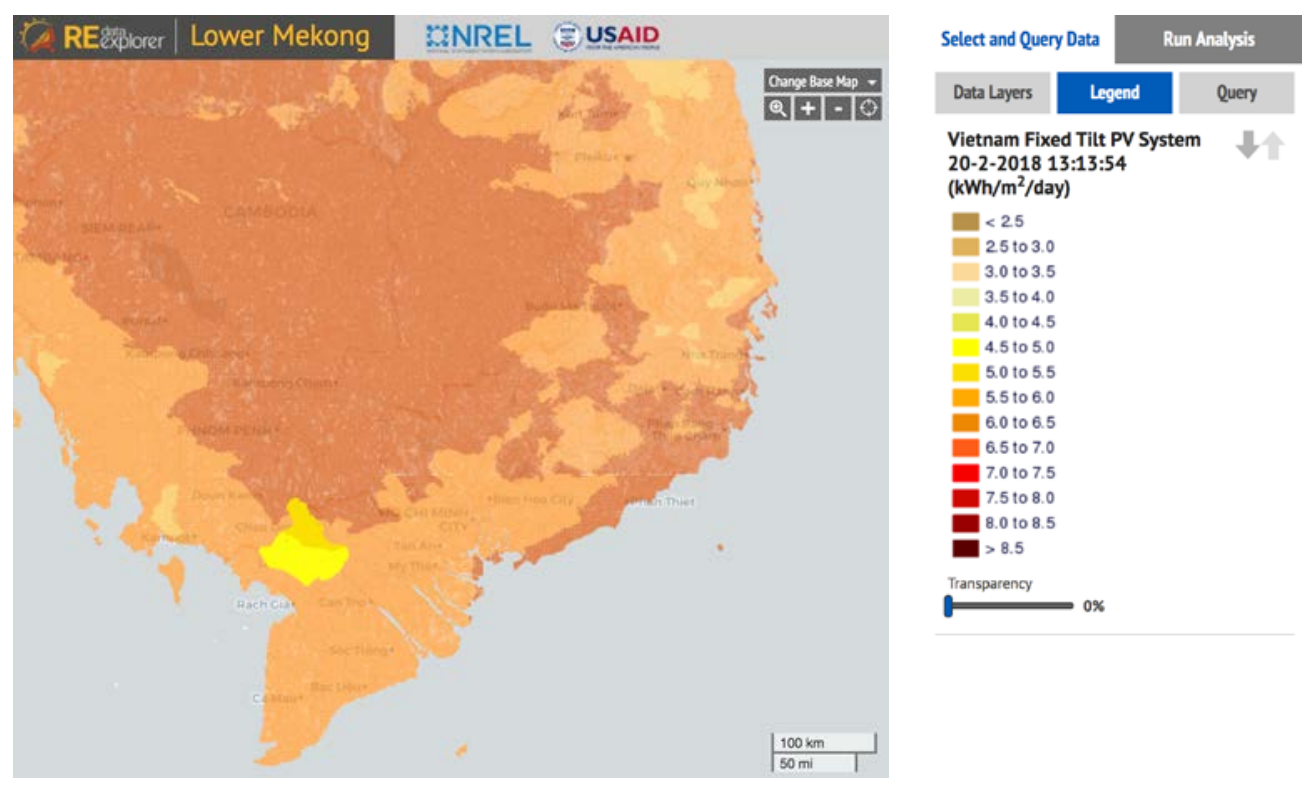

This report is available at no cost from the National Renewable Energy Laboratory at www.nrel.gov/publications. 


\section{Support Resources}

The RE Data Explorer website (www.re-explorer.org), which hosts the RE Data Explorer, provides resources, trainings, data sources, and expert assistance to support renewable energy geospatial analysis and decision-making, including:

- Tutorials that walk users through the RE Data Explorer and analyses in a guided format

- Technical potential webinars and other training resources

- A decision guide (Cox et al. 2018) to support links across data, analysis, and decision-making for renewable energy development

- Information on data included in the RE Data Explorer for each country as well as a spreadsheet to help users assess the data needs for analyses within the RE Data Explorer.

\section{References}

Brown, Austin, Philipp Beiter, Donna Heimiller, Carolyn Davidson, Paul Denholm, Jennifer Melius, Anthony Lopez, Dylan Hettinger, David Mulcahy, and Gian Porro. 2016. Estimating Renewable Energy Economic Potential in the United States: Methodology and Initial Results. Golden, CO: National Renewable Energy Laboratory. NREL/TP-6A20-64503. https://www.nrel.gov/docs/fy15osti/64503.pdf

Cox, Sadie, Anthony Lopez, Andrea Watson, Nick Grue, and Jennifer E. Leisch. 2018. Renewable Energy Data, Analysis, and Decisions: A Guide for Practitioners. National Renewable Energy Laboratory. NREL/TP-6A20-68913. https://www.nrel.gov/docs/fy18osti/68913.pdf.

Lopez, Anthony, Billy Roberts, Donna Heimiller, Nate Blair, and Gian Porro. 2012. U.S. Renewable Energy Technical Potentials: A GIS-Based Analysis. Golden, CO: National Renewable Energy Laboratory. NREL/TP-6A20-51946. https://www.nrel.gov/docs/fy12osti/51946.pdf.

Mone, Christopher, Maureen Hand, Mark Bolinger, Joseph Rand, Donna Heimiller, and Jonathan Ho. 2017. 2015 Cost of Wind Energy Review. Golden, CO: National Renewable Energy Laboratory. NREL/TP-6A20-66861. https://www.nrel.gov/docs/fy17osti/66861.pdf.

NREL (National Renewable Energy Laboratory). 2016. India Solar Resource Data. Golden, CO: National Renewable Energy Laboratory. NREL/FS-7A40-66070. https://www.nrel.gov/docs/fy16osti/66070.pdf.

Perez R., P. Ineichen, K. Moore, M. Kmiecik, C. Chain, R. George and F. Vignola, (2002): A New Operational Satellite-to-Irradiance Model. Solar Energy 73, 5, pp. 307-317.

Perez R., P. Ineichen, M. Kmiecik, K. Moore, R. George and D. Renné, (2004): Producing Satellite-Derived Irradiances in Complex Arid Terrain. Solar Energy 77, 4, 363-370. 
Perez, R., T. Cebecauer, M. Suri, (2013): Semi-Empirical Satellite Models, in: Solar Resource Assessment and Forecasting (Editor Jan Kleissl), Elsevier, 2013

Ong, Sean, Clinton Campbell, Paul Denholm, Robert Margolis, and Garvin Heath. 2013. LandUse Requirements for Solar Power Plants in the United States. Golden, CO: National Renewable Energy Laboratory. NREL/TP-6A20-56290. http://www.nrel.gov/docs/fy13osti/56290.pdf. 


\section{Appendix: Resource Analysis to Produce Capacity Factors}

This appendix lists the steps for analyzing a resource to produce capacity factors.

PV

Data for PV generation potential were sourced as follows, and the processing steps for each source are outlined below.

\section{SolarGIS/World Bank}

SolarGIS, commissioned by the World Bank, provided solar resource and generation data for the entire globe at no cost. ${ }^{11}$ The PVOUT data set provides PV power potential as $\mathrm{kWh} / \mathrm{kWp}$ (kilowatt peak), which is essentially the energy generation per $\mathrm{kW}$ or installed capacity. Dividing the annual generation from this data set the number of hours in a year $(8,760)$ returns the capacity factor. These capacity factors are subject to the PV system assumptions used by SolarGIS. A complementary spreadsheet available on the RE Explorer website is also available describing these assumptions in detail.

\section{SUNY/Solar Consulting Services and Vaisala}

The State University of New York and Solar Consulting Services developed solar resource data for India using the semi-empirical satellite model developed by Perez et al. (2002, 2004, and 2013) as part of the India-U.S. Energy Dialog. And, Vaisala provided proprietary hourly solar resource data for the Central Asia region that was used for evaluating generation potential.

NREL's Renewable Energy Potential (reV) model uses NREL's System Advisor Model ${ }^{12}$ (SAM) to develop generation potential, and capacity factors using time-series resource data as inputs. The reV model allows for the spatially and temporally varying evaluation of resource and creation of spatially continuous capacity factor data, as used by the RE Data Explorer Technical Potential Tool. By feeding hourly (or subhourly) resource data, including the metrics DNI, diffuse horizontal irradiance (DHI), air temperature at the surface, and wind speed at the surface, the annual generation potential is calculated for every resource pixel. The resulting capacity factor data sets allow for the estimation of annual PV generation across landscapes.

\section{Wind}

Data for wind generation potential were sourced from the Technical University of Denmark (DTU) and NREL. NREL produced subhourly wind resource data using the Weather Research and Forecasting ${ }^{13}$ (WRF) model. DTU provides global wind speeds at 80-m, 100-m, and 120-m hub heights.

\footnotetext{
11 “Global Solar Atlas: Global Wind Atlas | energydata.info” http://globalsolaratlas.info/

12 “System Advisor Model (SAM),” https://sam.nrel.gov/

13 “Weather Research and Forecasting Model,” National Center for Atmospheric Research, Mesoscale and Microscale Meteorology Laboratory, https://www.mmm.ucar.edu/weather-research-and-forecasting-model
} 


\section{DTU}

The Technical University of Denmark (DTU) created global wind speed data that can be used as the basis for developing generation potential estimates. Lacking hourly (or subhourly) resource data, NREL used general assumptions to develop capacity factors for five generic turbines (Mone et al. 2017) based on the wind speed in the DTU wind data set.

A Weibull $\mathrm{k}$ factor of 2 combined with losses of $15 \%$ and $98 \%$ availability (which cumulatively equal $16.7 \%$ overall losses) were applied to the wind speeds to generate capacity factors at on quarter wind class bins. This means for every $1 / 4 \mathrm{~m} / \mathrm{s}$, a capacity factor was generated using the DTU wind speed data.

\section{reV / WRF Modelling (Central Asia)}

Similarly to the solar resource evaluation listed above, the reV model used subhourly wind resource data, including the metrics wind speed, air temperature, and air pressure to estimate annual generation potential. The resulting capacity factors are used as inputs to the RE Data Explorer technical potential analysis. System assumptions used for the capacity factors are available in a complementary user guide spreadsheet on the RE Explorer website.

CSP

Development of capacity factors for CSP are based on Lopez et al. (2012). 


\section{USAID \\ FROM THE AMERICAN PEOPLE}

United States Agency for

International Development

1300 Pennsylvania Avenue NW

Washington, DC 20523

+1-202-712-0000 • www.usaid.gov

\section{ONREL}

National Renewable Energy Laboratory

15013 Denver West Parkway

Golden, CO 80401

+1-303-275-3000 • www.nrel.aov

NREL is a national laboratory of the U.S.

Department of Energy, Office of Energy

Efficiency \& Renewable Energy, operated by the Alliance for Sustainable Energy, LLC.

NREL/TP-6A20-71532 • May 2018

\section{CONTACTS}

Jennifer E. Leisch, Ph.D.

USAID-NREL Partnership Manager

U.S. Agency for International Development

Tel: +1-303-913-0103

Email: jleisch@usaid.gov

Sadie Cox

National Renewable Energy Laboratory Tel: +1-303-384-7391

Email: sadie.cox@nrel.gov 